\title{
PRELIMINARY RESULTS OF OCEAN MAGNETIC OBSER- VATIONS ON THE CARNEGIE FROM ST. HELENA TO CAPE TOWN AND THENCE TO COLOMBO, CEYLON, APRIL TO JUNE, 1920.1
}

\author{
Bx J. P. Ault, Commanding the Carnegie.
}

(Observers: J. P. Ault, H. F. Johnston, R. R. Mills, H. R. Grummann, and R. Pemberton.)

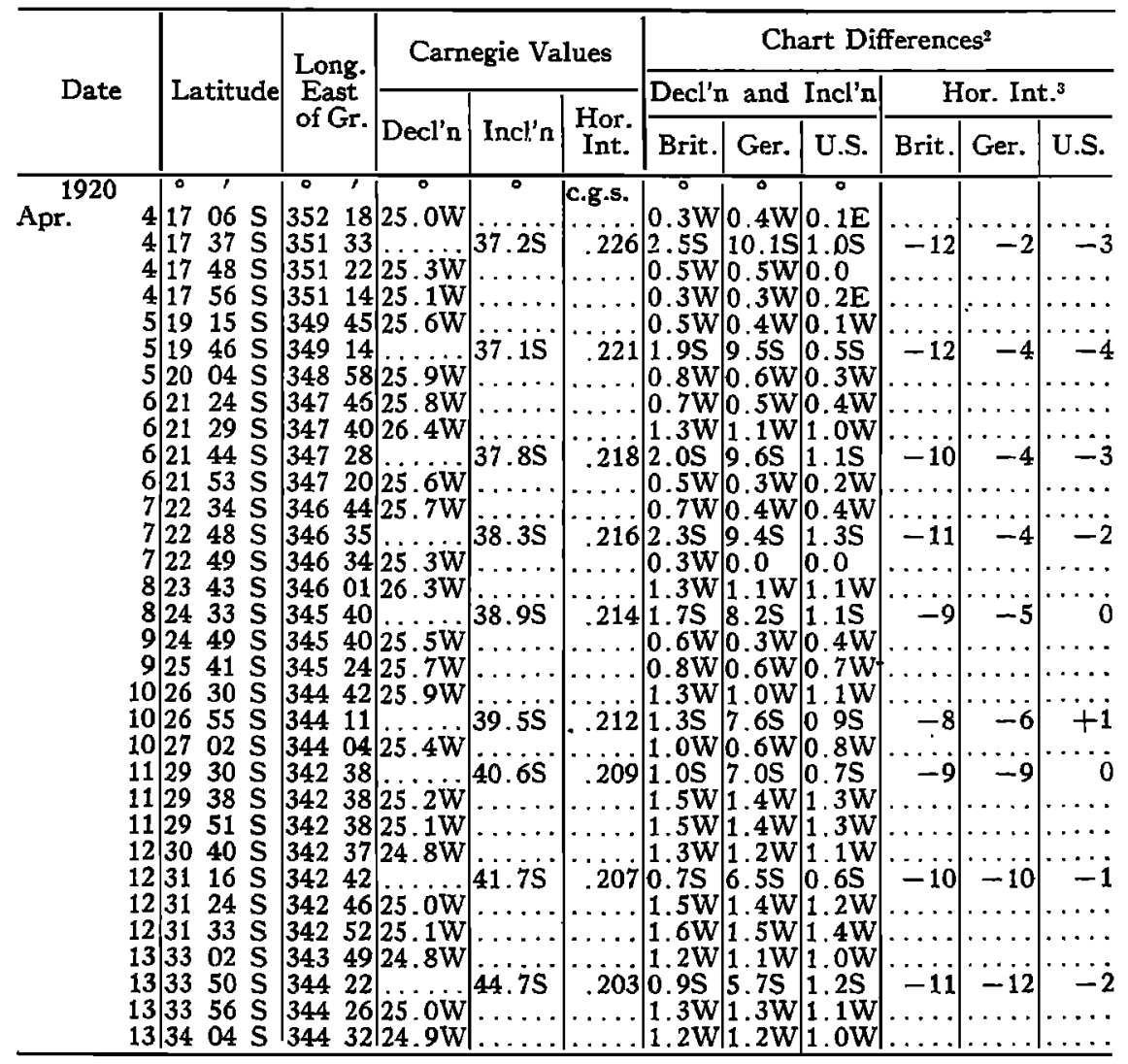

For previouts table, see Terr. Mag. vol. 25, p. 49.

Charts used for comparison: U. S. Hydrographic Office Charts Nos. 1700,1701 and 2406 for 1920; British Admiralty Charts No. 3775 for 1917 ; 3598 and 3603 for 1907; Reichs-Marine-Amt Charts Tit. XIV, No. 2 for 1910 ; Tit. XIV, Nos. 2a and 2b for 1905. The chart differences are obtained by subtracting chart values, derived as explained in previous sentence, from the observed Carnegie values. The letter $\mathrm{E}$ signifies that the chart value for east declination is smaller, or the chart value for west declination larger, than the Carnegie value; $W$ signifies the reverse. The letter $\mathbf{N}$ signifies that the derived chart value for northerly inclination is smaller, or for southerly inclination larger, than the Carnegie value; $S$ signifies the reverse. The plus sign signifies that the derived chart value for horizontal intensity is smaller than the Camegic value, the minus sign meaning, of course, the reverse. Secular corrections have been applied to declinations only.

Expressed in units of third decimal C. G. S. 


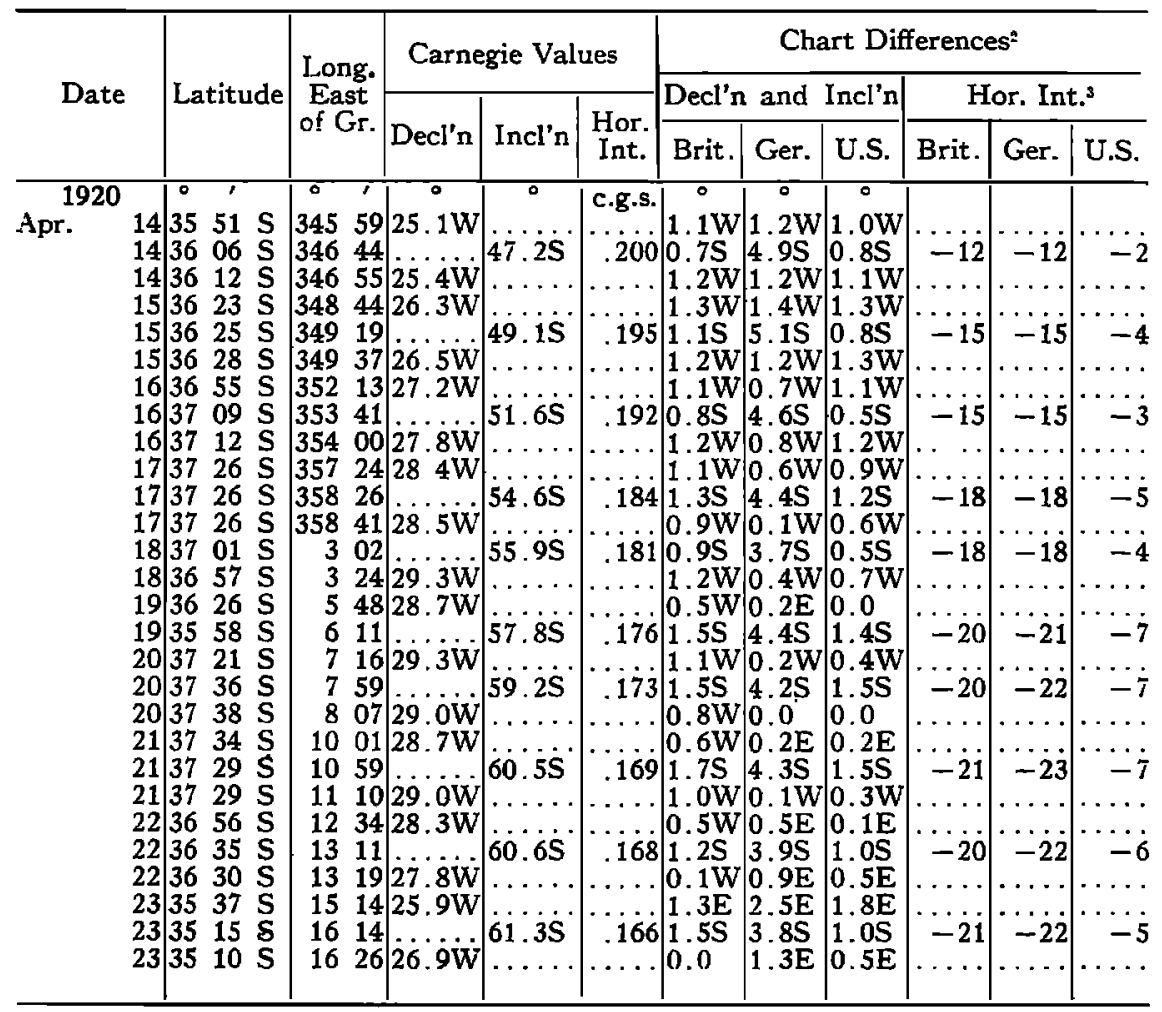

Notes on Trip From St. Helena to Cape Town.

We sailed from St. Helena at 3 P. M., April 3, and after three days of sailing in the southeast trade winds we entered the region of variable winds and calms on April 6. Considerable lightning accompanied by heavy thunder was noted during some heavy squalls in the middle of the South Atlantic Ocean, far from land. By April 11 we had crossed this region of variable winds and had picked up the westerly winds. A moderate to fresh gale blew from the northwest, shifting to southwest, during April 13 and 14 .

On April 15 it was planned to make a brief stop at Tristan Island, but, unfortunately, the wind hauled more to the southward and we were unable to make the island. It was plainly visible at a distance of 50 miles on the morning of April 15, rising out of the sea an almost perfect cone. 
For four days after sighting Tristan we averaged over 210 miles per day. The usual cycle of atmospheric pressure-changes, with their corresponding changes in the wind for these regions, were experienced. With high pressure northerly winds blow, shifting to northwest and west as the pressure decreases. The more rapid the decrease in pressure the stronger the wind blows. At the lowest point the wind shifts to the southwest and blows hard if the pressure increases rapidly, shifting to south and southeast as the pressure rises, finally jumping to northeast as the highest point is reached. These heavy westerly winds were followed by light southerly to northerly winds during April 18 to 22, shifting to northwest on April 23 and blowing stronger.

We arrived at Cape Town on April 24 after 21 days at sea. The average daily run was 152 miles. Declination observations were made daily and the usual program of magnetic and electric work was carried out.

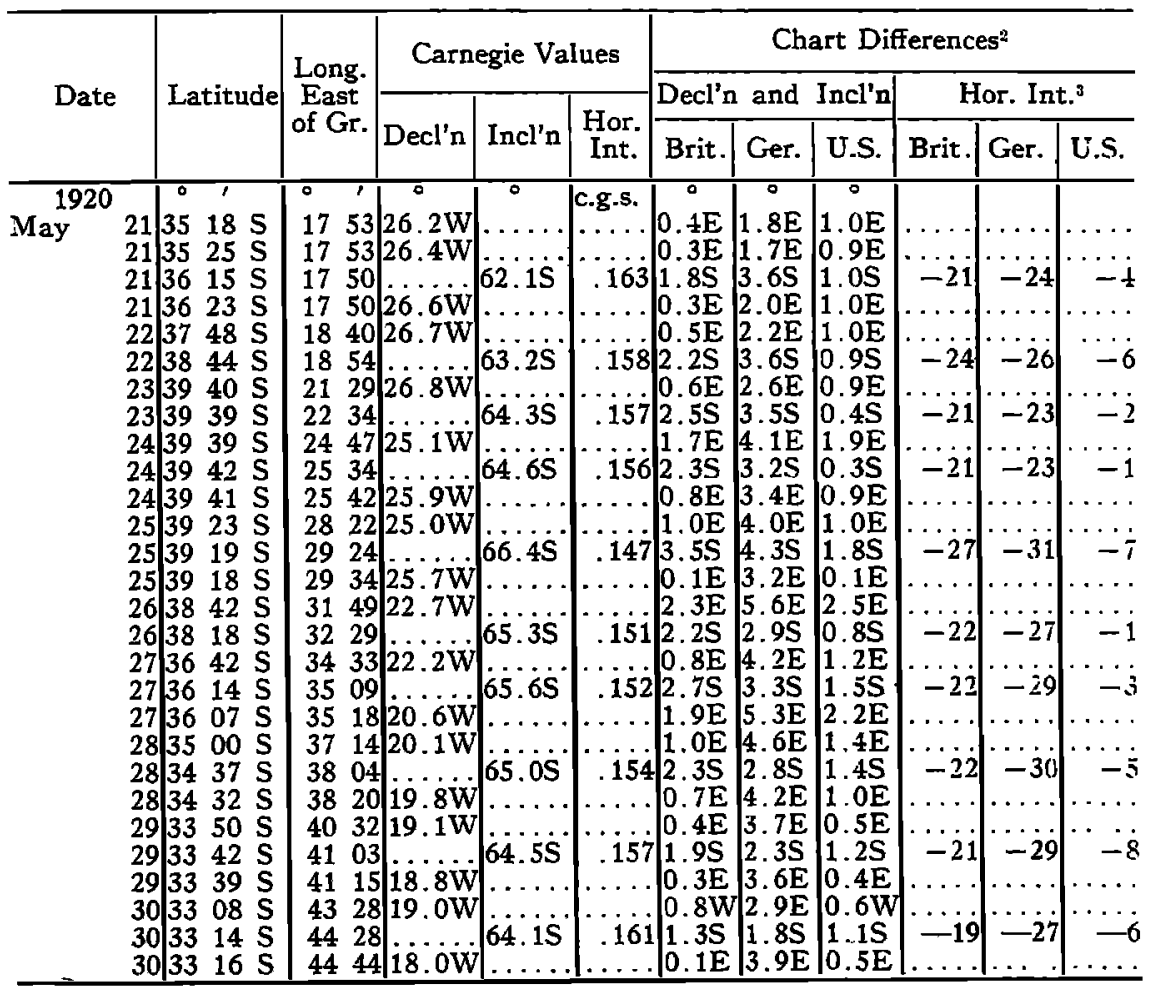




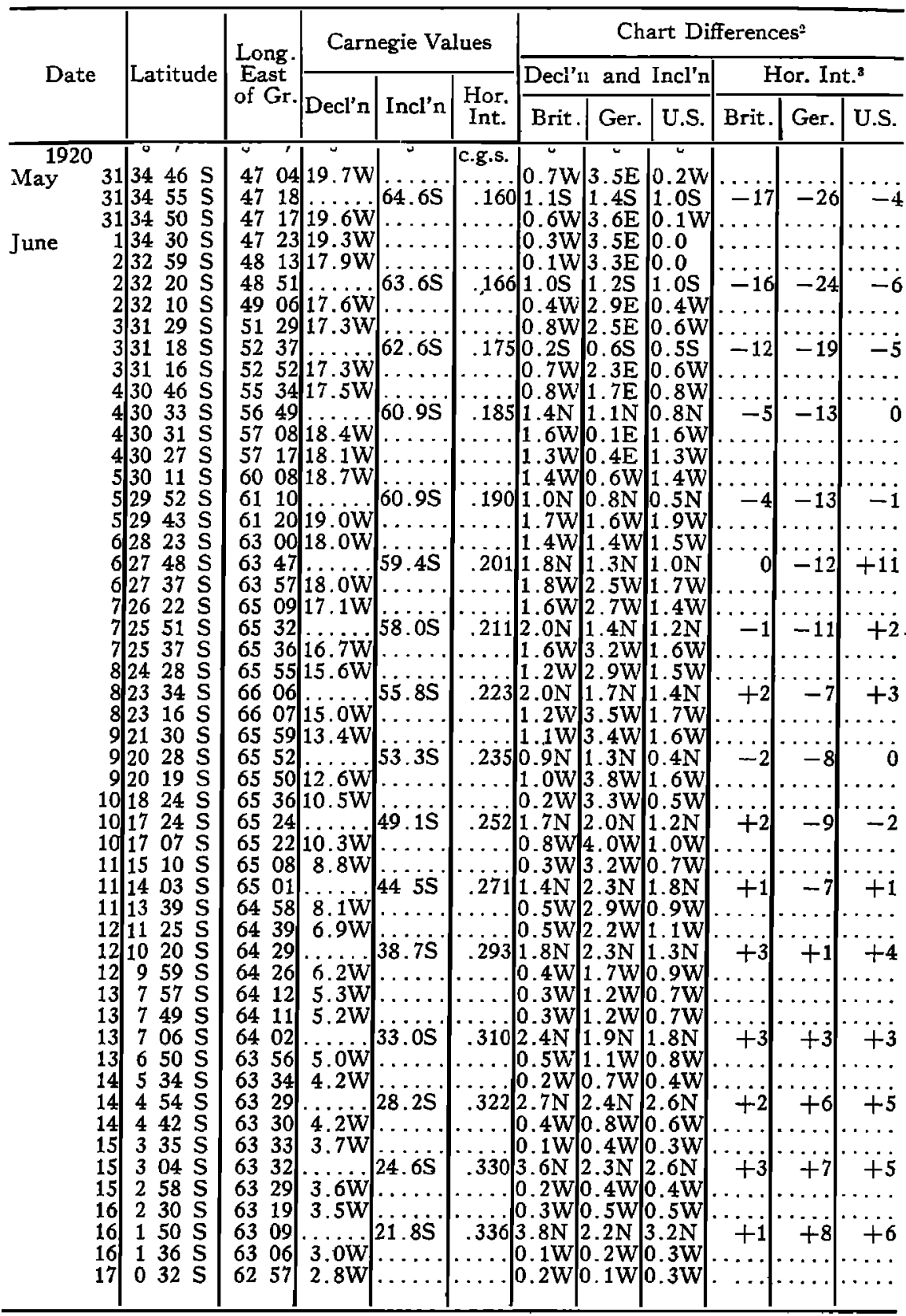




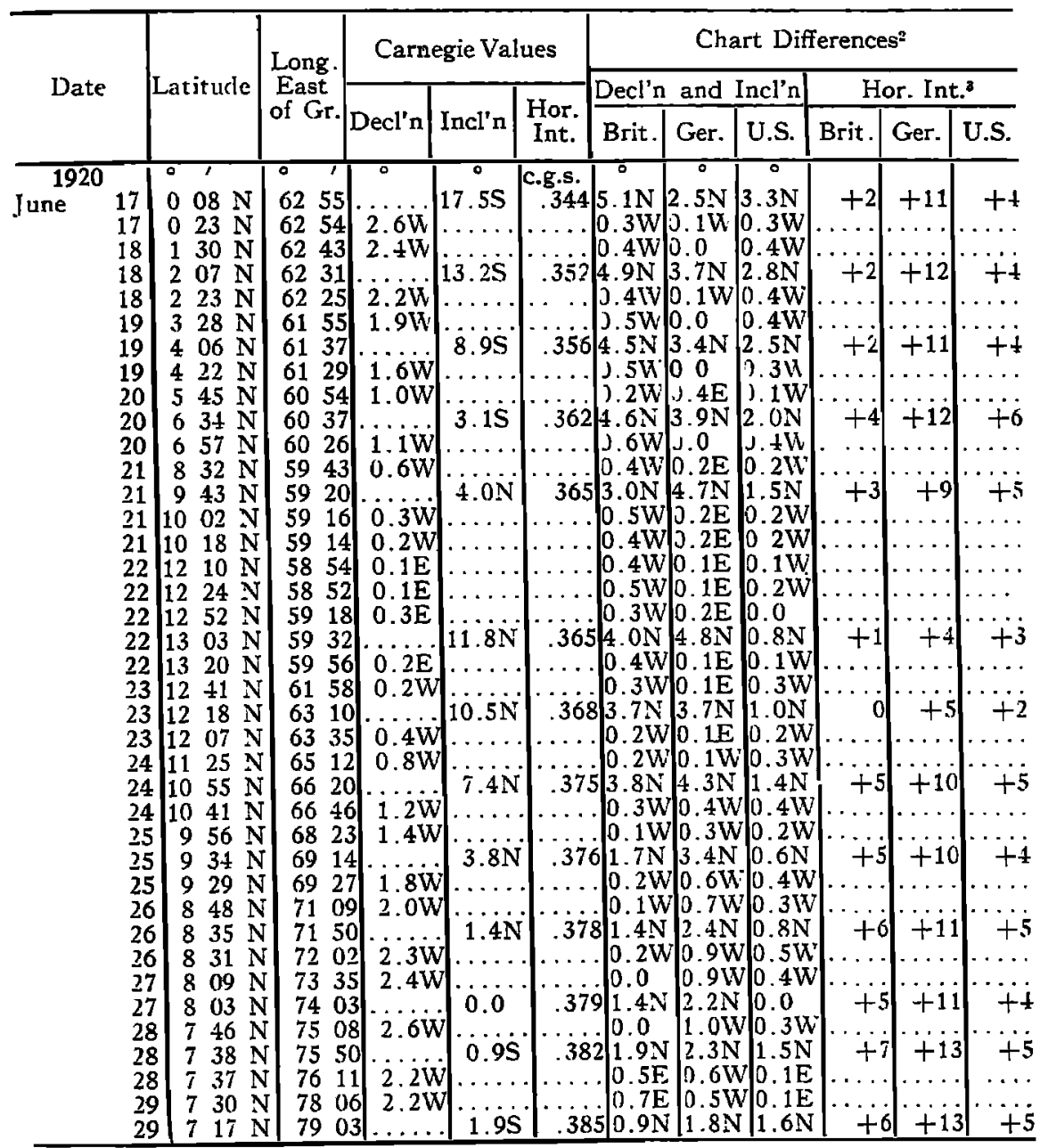

\section{Notes on TRIP from Cape Tow to Colombo.}

At 3 P. M., May 20, 1920, the Carnegie left the dock at Cape Town and proceeded to sea under tow, the departure having been delayed a few days by matters relating to the crew. The Cape Town harbor authorities gave the Carnegie every consideration in the way of free dockage, free pilotage, and free towboat service, a courtesy very much appreciated. After they had towed the vessel well out to sea we started our own engine and ran until after midnight, when a breeze sprang up from the northwest and the Carnegie was on her way to Colombo. 
On May 22 a fresh gale sprang up from the southwestward and it became necessary to keep the vessel off to the eastward. On May 23 the gale moderated but the wind shifted to the southward, thus preventing our making as far south as had been planned. On May 24 another gale commenced from the northward and continued to blow throughout May 25 and 26. Fortunately its direotion was such that the vessel could keep on her course without too much strain and so good progress was made. Declination observations were made daily and usually twice daily in regrons where none had been secured during the 1911 cruise. On May 30 a head wind was encountered and the vessel was driven to the southeastward out of her course for one day, the only head wind encountered during the trip. This head wind was followed by a calm which lasted 10 hours, the wind shifting from northeast to southeast, dying out, and again springing up from the same quarter. Another gale developed on June 2 and continued on June 3,4 , and 5 , the vessel making over 200 miles daily-running before the gale.

June 5 and 6 saw a gradual change of course leading up into the Indian Ocean. The region of the westerlies was gradually left behind and on June 8 , after three hours of calm, the southeast trade wind was picked up. For one week excellent weather prevailed and the vessel averaged over 180 miles per day while crossing the southeast trade wind belt. The southwest monsoon was encountered on June 15, after about four hours of calms. For over four days this monsoon was very light but on June 20 it began to blow more strongly, and finally on June 22 it developed into a gale and blew for over two days. During this gale the agonic line was crossed twice, as also the Carnegie's track of 1911 in the Arabian Sea. Owing to the strength of the monsoon and its tendency to blow more from the southward than from the westward, it was decided not to go farther north into the Arabian Sea. To make sure of weathering the Laccadive Islands the course was shaped for Colombo on June 22, after being certain that we were well to the northward of the agonic line. At midnight on June 26 we sighted the light on Minikoi Island, as expected. Eastward of Minikoi the southwest monsoon was very light, so that we did not reach Colombo until $10^{\mathrm{h}} 30_{\mathrm{m}}^{\mathrm{A}}$. M., June 30 , after having been hove to all night.

Declination observations were made twice daily on 29 days, once daily on only 6 days, three times daily on three days, and four times on one day, when crossing the agonic line. The chart errors in declination for the southern part of the Indian Ocean averaged over $1^{\circ}$, sometimes reaching $2 .^{\circ} 5$. In the northern part of the Indian Ocean they were less than $00^{\circ} 5$. Inclination and horizontal intensity observations were made daily with the exception of one day, when the vessel had been becalmed.

The total distance covered from Cape Town to Colombo was 6,665 nautical miles, giving an average of 163.4 miles for 40.8 days of the trip. This is a very high average for the Carnegie for a trip of over 40 days. Rain or precipitation fell on 29 out of 41 days. 